\title{
QUALIDADE DOS EFLUENTES DE SISTEMAS DE TRATAMENTO BIOLÓGICO UASB E UCT PARA REÚSO AGRÍCOLA
}

\author{
Hosineide de Oliveira Rolim* \\ Jarbas Rodrigues Chaves** \\ Ana Bárbara de Araújo Nunes*** \\ Heraldo Antunes Silva Filho***** \\ Elivânia Vasconcelos Moraes dos Santos ${ }^{* * * * *}$
}

RESUMO: O presente trabalho avaliou as condições de reúso dos efluentes finais de dois sistemas de tratamento biológico de esgotos: um reator UASB e um sistema de lodo ativado frente aos padrões recomendados da Organização Mundial de Saúde (OMS) e os critérios de qualidade de água para irrigação. As variáveis avaliadas foram pH; CE; $\mathrm{Ca}^{2+} ; \mathrm{Mg}^{2+} ; \mathrm{Na}^{+}$; Cl; NTK; Fósforo total; DQO; Turbidez; SST; amônia; coliformes termotolerantes e ovos de helmintos; RAS; e salinidade. Os resultados demonstraram que os sistemas só cumprem parcialmente os requisitos para reúso agrícola. O sistema UASB apresentou SST e turbidez como limitantes na irrigação localizada, concentração de coliformes apenas para irrigação restrita em subsuperfície, NTK acima de $30 \mathrm{mg. \textrm {L } ^ { - 1 }}$ e a contagem $>1,0$ ovo. $\mathrm{L}^{-1}$ de helmintos que inviabiliza o reúso. O sistema UCT apresentou menos limitações de acordo com os parâmetros avaliados, com inviabilidade de reúso direto principalmente devido à turbidez, coliformes e ovos de helmintos.

PALAVRAS-CHAVE: Lodo Ativado; Reatores; Reúso Agrícola; UASB.

\section{QUALIT Y OF EFFLUENTS FROM UASB AND UCT BIOLOGICAL TREATMENT SYSTEMS FOR AGRICULTURAL REUSE}

ABSTRACT: The reuse of affluents from two biological sewage treatment systems is assessed. The study comprised a Upflow Anaerobic Sludge Blanket (UASB) reactor and an activated sludge system according to standards recommended by the World

Doutora em Engenharia Civil da Universidade Federal do Ceará (UFC), Fortaleza, CE, Brasil; E-mail: hosineiderolim@yahoo.com.br

** Mestre em Tecnologia e Gestão Ambiental pelo Instituto Federal do Ceará (IFCE), Fortaleza, CE, Brasil.

*** Docente Doutora do Departamento de Engenharia Hidráulica e Ambiental da Universidade Federal do Ceará (UFC), Fortaleza, CE, Brasil.

${ }^{* * * *}$ Docente Doutor do Instituto Federal do Ceará (IFCE), Campus Limoeiro do Norte, CE, Brasil.

${ }^{* * * * *}$ Docente Doutora do Instituto Federal do Ceará (IFCE), Campus Limoeiro do Norte, CE, Brasil. 
health Organization and water quality criteria for irrigation. Evaluated variables included $\mathrm{pH}$; CE; $\mathrm{Ca}^{2+} ; \mathrm{Mg}^{2+} ; \mathrm{Na}^{+}$; Cl; NTK; total phosphorus; OCD; Turbidity; TSS; ammonia; thermotolerant coliforms and helminth eggs; RAS; and salinity. Results showed that system partially comply with requirements for agricultural reuse. The UASG system showed TSS and turbidity as limiting in irrigation; coliform concentration for restricted sub-surface irrigation; NTK above $30 \mathrm{mg} . \mathrm{L}^{-1}$ and counts $>1.0$ egg. $\mathrm{L}^{-1}$ of helminths that make reuse unviable. UCT system had less limitations according to the parameters evaluated, with non-viability of direct reuse mainly due to turbidity, coliforms and helminths eggs.

KEY WORDS: Activated Sludge; Reactors; Agriculture Reuse; UASB.

\section{INTRODUÇÃO}

Embora seja um recurso natural renovável, a água é um recurso finito, posto que não atenderá perpetuamente à ilimitada e crescente necessidade humana. A quantidade de água que flui no ciclo hidrológico não é compatível ao aumento contínuo da demanda hídrica nos diversos setores, sendo esta oferta natural de água doce esgotável.

É diante desse cenário de elevado crescimento na demanda por água com qualidade para uso doméstico, industrial, comercial e agrícola que, unida à escassez natural, tem acelerado a busca por fontes alternativas para abastecimento para diferentes fins potáveis e não potáveis. Entre estas fontes adicionais podem-se citar os processos de dessalinização, as águas de run-off (escoamento) e esgoto tratado (ORON et al., 1999).

Os efluentes de estação de tratamento de esgoto são águas residuárias ricas em matéria orgânica e nutrientes que podem ocasionar sérios impactos ambientais quando lançadas nos corpos d'água (SANTOS, 2008). Entretanto, estas mesmas características podem, com manejo adequado, trazer benefícios quando aplicados a sistemas de produção agrícola.

De acordo com Telles e Costa (2007), a aplicação do tratamento de esgoto no solo é uma forma efetiva do controle da poluição e uma alternativa viável para aumentar a disponibilidade hídrica das regiões áridas e semiáridas.

Conforme Hespanhol (2003), devido às grandes vazões necessárias no 
setor agrícola, a priorização para institucionalizar a prática de reúso assume grande importância. $\mathrm{O}$ autor ressalta que já existe um avanço significativo nas duas últimas décadas no uso de esgoto para fins agrícolas, devido a fatores como: dificuldade crescente de identificar fontes alternativas de água para irrigação; custo elevado de fertilizantes; a segurança de que os riscos de saúde pública e impactos sobre o solo são mínimos, se as preocupações adequadas são efetivamente tomadas; os custos elevados dos sistemas de tratamento, necessários para a descarga de efluentes em corpos receptores; a aceitação sociocultural da prática do reúso agrícola; e o reconhecimento do valor intrínseco da prática.

Dessa forma a aplicação de água residuária na agricultura necessita de estudos da viabilidade do projeto, avaliando previamente os benefícios da prática. Entre estes vale destacar a possibilidade de uma maior produtividade agrícola devido a um incremento de nutriente presente nos efluentes em relação ao uso de água naturais, podendo reduzir ou eliminar a necessidade de emprego de fertilizantes comerciais (HESPANHOL, 2003).

No Brasil, a prática intensiva de reúso ainda enfrenta alguns desafios. A falta de disciplinamento para o reúso de água impede a universalização desta prática. A falta de um arcabouço legal como a criação de uma lei federal e padrões reguladores para dar suporte a este importante instrumento de gestão ambiental faz com que as práticas aconteçam de forma pontual (BRITO, 2012).

Outro fator importante que impede o avanço sistemático da prática, de acordo com Brito (2012), é a falta de consenso sobre a qualidade dos efluentes tratados, aspectos como os riscos sanitários envolvidos com risco nulo ou risco potencial zero (critério da Califórnia), ou com nível de risco aceitável (critério da Organização Mundial da Saúde) ainda são controversos por muitos.

Além disso, o reúso agrícola pressupõe um conhecimento da qualidade da água a ser utilizada para que não venha ocasionar impactos ambientais e disseminação de doenças. $\mathrm{O}$ uso indiscriminado de efluentes brutos ou parcialmente tratados pode resultar na disseminação de infecções causadas por nematóides, bactérias, protozoários e vírus, prejudicando os trabalhadores e os consumidores finais dos produtos irrigados.

Os reatores anaeróbios sempre se configuram entre as principais opções 
quando se analisam as alternativas mais viáveis para tratamento de esgoto. Entretanto, esses sistemas apresentam-se com capacidade mais limitada para a remoção de matéria orgânica e pequena (caso exista) remoção de nutrientes e patógenos, demandando, em geral, alguma forma de pós-tratamento seja para o lançamento em corpos receptores, seja para o reúso (CHERNICHARO et al., 2006).

A tecnologia anaeróbia tem sido estendida para o tratamento de despejos domésticos, principalmente através de reatores tipo Upflow Anaerobic Sludge Blanket Reactors (UASB), na tradução para o português, Reatores Anaeróbios de Fluxo Ascendente e Manta de Lodo, tecnologia muito atrativa, tanto economicamente quanto em termos de eficiência na remoção de material orgânico, para os países de clima tropical e subtropical em que a temperatura se mantém acima de $20{ }^{\circ} \mathrm{C}$ não interferindo na atividade dos microrganismos anaeróbios (VAN HAANDEL; LETTINGA, 1994).

Os sistemas de lodo ativado (SLA), de um modo geral, se apresentam bastante difundidos pelo mundo e são utilizados principalmente quando se deseja uma elevada qualidade do efluente com baixos requisitos de área (VON SPERLING, 2002). Estes sistemas apresentam diversas variações, quando se considera a remoção biológica conjunta de nutrientes (N e P).

Von Sperling (2002) cita os principais processos utilizados em SLA destacando: o processo A2O (Phoredox de três estágios), processo Bardenpho de cinco estágios (Phoredox), processo UCT, processo UCT modificado e reatores de operação intermitente (batelada).

Contudo, a nomenclatura mais adequada é considerar como processos a nitrificação, desnitrificação e biodesfosfatação e os principais sistemas de lodo ativado com remoção de nutrientes como: Phoredox (sistema com dois reatores, um primeiro anaeróbio seguido de um aeróbio, e uma recirculação do decantador para o primeiro reator), Bardenpho (sistema com no mínimo 3 reatores com pré e pós desnitrificação e um reator aeróbio central, com recirculação do decantador e do aeróbio para o primeiro reator anóxico) e o sistema University of Cape Town (UCT), que consiste em, no mínimo 4 reatores, sendo estes em série, anaeróbio, anóxico, aeróbio e anóxico, demonstrando maior efetividade na remoção de nitrogênio e fósforo (VAN HAANDEL; MARAIS, 1999).

No sistema UCT, proposto por Rabinowitz e Marais (1980), o principal 
aspecto que o distingue dos demais é o fato de evitar a introdução de nitrato na zona anaeróbia, dirigindo dessa forma a recirculação de lodo antes para uma zona anóxica e posteriormente para a zona anaeróbia, dessa forma potencializando a remoção de fósforo.

O objetivo deste trabalho foi avaliar a qualidade do efluente de dois reatores biológicos (um reator UASB e um sistema de lodo ativado) tratando o esgoto gerado em um campus universitário, com a perspectiva de reúso agrícola, avaliando os riscos às plantas e ao solo de acordo com os critérios de qualidade de água para irrigação.

\section{MATERIAL E MÉTODOS}

A pesquisa foi desenvolvida nas instalações do Centro Experimental de Tratamento de Esgoto (CETE), do Instituto Federal do Ceará (IFCE), Campus Limoeiro do Norte, que trata parte das águas residuárias geradas na instituição. Nesse local foram montados dois sistemas de tratamento biológico de esgoto: um sistema de tratamento anaeróbio (reator UASB) e um sistema de lodo ativado (UCT).

\subsection{SISTEMA UASB}

O sistema anaeróbio tipo UASB, em escala laboratorial, tinha volume útil de 24 L e foi construído com tubos e conexões em material PVC, sendo constituído de um tubo de diâmetro de $100 \mathrm{~mm}$ e altura de $2,15 \mathrm{~m}$ e um cap no fundo. Um defletor foi instalado na parte superior, inclinado com o eixo vertical a um ângulo de $45^{\circ}$ de $0,85 \mathrm{~m}$ de comprimento para a separação das fases e a saída do efluente tratado. A configuração utilizada é proposta para tratar pequenas vazões.

\subsection{SISTEMA UNIVERSITY OF CAPE TOWN (UCT)}

O sistema de lodo ativado tipo UCT, em escala piloto, era composto por 4 reatores sequenciais: 1 reator anaeróbio (R1) com um volume de 9,0 L, seguido por 1 reator anóxico (R2) de 9,0 L, 1 reator aerado (R3) com capacidade de 10 L, e 1 
anóxico (R4) de 9,0 L, seguidos por 1 decantador de 4,0 L.

Nesse sistema ocorriam três recirculações de licor misto: a primeira recirculação seguia do reator anóxico (R2) para o reator anaeróbio (R1) com o propósito de recircular licor misto sem a presença de oxidante (no caso nitrato) favorecendo um ambiente anaeróbio propício à remoção de fósforo. A segunda recirculação ocorria a partir do decantador para o reator anóxico (R2), com o objetivo de favorecer a desnitrificação pelo aumento da concentração de biomassa. A terceira recirculação partia do reator aerado (R3) para o R2 objetivando inserir nitrato e favorecer a desnitrificação.

Para promover a mistura do licor misto em três reatores, foram utilizados agitadores mecânicos cuja finalidade das misturas era evitar a decantação do lodo e proporcionar o contato da biomassa com o esgoto a ser tratado. O efluente tratado era armazenado em um recipiente de $20 \mathrm{~L}$ para posterior análise de qualidade.

\subsection{ANÁLISES DA QUALIDADE DOS EFLUENTES}

Para o monitoramento do desempenho dos sistemas eram coletadas semanalmente amostras da entrada (esgoto afluente) e da saída do sistema (efluente tratado). As coletas foram realizadas no período de março de 2011 a janeiro de 2013. Dos pontos de coleta foram investigados parâmetros físico-químicos e microbiológicos, incluindo $\mathrm{pH}$, demanda química de oxigênio (DQO), condutividade elétrica (CE), turbidez, sólidos suspensos totais (SST), $\mathrm{Cl}, \mathrm{Ca}^{2+}, \mathrm{Mg}^{2+}, \mathrm{Na}^{+}$, fósforo total (P), amônia $\left(\mathrm{NH}_{3}\right)$, Nitrogênio Kjeldahl (NTK), coliformes termotolerantes de acordo com os métodos padronizados para análises de água e esgoto (APHA et al., 2012) e ovos de helmintos através do método de Bailenger Modificado (AYRES; MARA, 1996).

Com o resultado das análises físicas e químicas dos efluentes dos sistemas UASB e UCT foi possível avaliar a qualidade quanto aos riscos de salinização, sodificação, toxicidade às plantas e potencial de fertilização de acordo com a classificação proposta por Ayres e Westcot (1991).

O parâmetro utilizado para avaliar a salinidade do efluente foi a condutividade elétrica (CE), em $\mu \mathrm{S} . \mathrm{cm}^{-1}$, classificando nas classes de nenhuma, moderada e severa restrição de uso quanto ao risco de salinização do solo.

Foi avaliada a razão de adsorção de sódio (RAS), calculada pela equação: 
RAS $=\mathrm{Na}^{+} /\left[\left(\sqrt{ } \mathrm{Ca}^{2+}+\mathrm{Mg}^{2+}\right) / 2\right]$. A avaliação conjunta da RAS e da CE permitiu analisar a sodicidade do efluente. Os resultados de cloretos e sódio foram utilizados para avaliar a toxicidade destes íons à planta. Para avaliar o potencial fertilizante dos efluentes foram monitorados os macronutrientes $\mathrm{N}$ e $\mathrm{P}$. O risco de obstrução dos sistemas de irrigação foi avaliado para os parâmetros de SST e pH.

A caracterização da matéria orgânica através da DQO permitiu avaliar se as concentrações eram significativas a fim de garantir um condicionamento do solo e que não afetasse na absorção de água pelas raízes.

Tanto os resultados de coliformes como de ovos de helmintos foram avaliados conforme os padrões sugeridos pela OMS (2006), que disciplina os limites para fins de reúso na irrigação irrestrita e restrita.

Os resultados obtidos foram submetidos à análise estatística sendo calculados valores médio, mínimo, máximo, desvio padrão e coeficiente de variação para cada parâmetro analisado nos dois períodos de operação dos reatores.

\section{RESULTADOS E DISCUSSÃO}

\subsection{VALORES DE PH EFLUENTE AOS SISTEMAS}

Os valores de $\mathrm{pH}$ efluente ao reator UASB para 85 amostras analisadas variaram em uma faixa relativamente ampla durante todo o período de monitoramento, mantendo-se entre 5,6 e 8,8. Essa variação ocorre porque microrganismos diferentes atuam nas distintas fases da digestão anaeróbia (em especial acidogênese que reduz o pH e metanogênese que eleva o $\mathrm{pH}$ ) e suas necessidades em termos de pH também diferem. A operação do sistema UASB apesar de simples pode sofrer influência de aspectos ambientais que alteram as predominâncias desses grupos microbianos (VAN HAANDEL; LETTINGA, 1994).

Entretanto, a maioria dos valores obtidos manteve-se na faixa ideal para irrigação que, conforme Ayres e Westcot (1991), são de 6,5 a 8,4. O pH fora dessa faixa favorece o desequilíbrio nutricional das culturas irrigadas.

Em relação ao sistema UCT, no período de monitoramento, o pH do esgoto 
tratado apresentou o valor mínimo de 5,1 e máximo de 8,3, com 93\% dos resultados de $\mathrm{pH}$ dentro da faixa ótima acima requerida para irrigação (Figura 1).

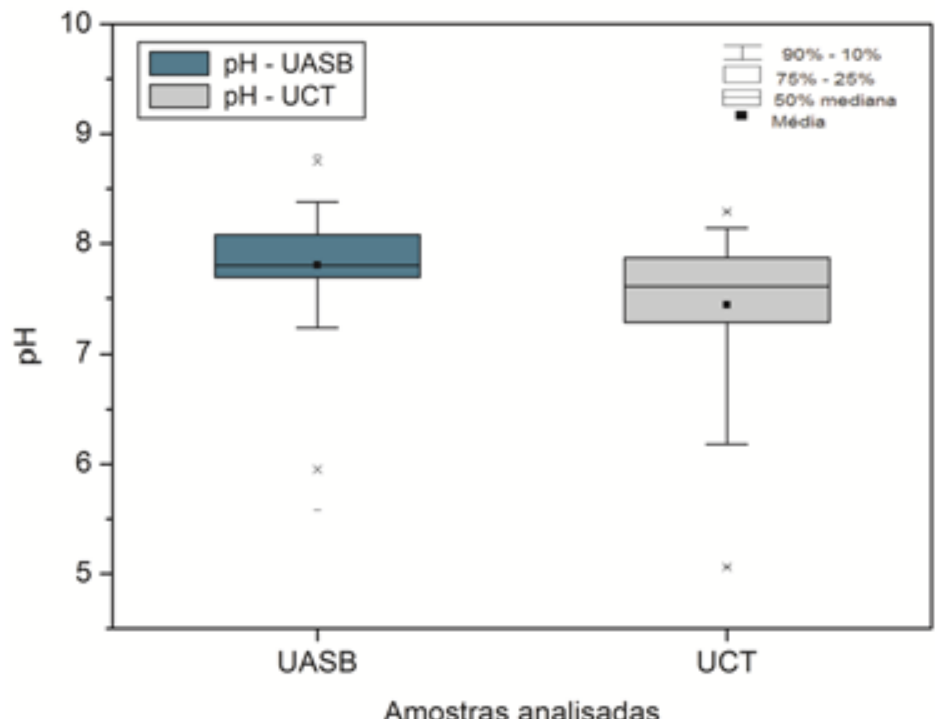

Figura 1. Valores de $\mathrm{pH}$ do efluente dos sistemas UASB e UCT

\subsection{TURBIDEZ}

As diretrizes da OMS (WHO, 2006), que regulamentam o uso de águas residuárias para irrigação, definem como critério de adequação para o uso irrestrito turbidez de 2,0 UNT, o mesmo critério da USEPA (2004) para culturas consumidas cruas, para processos de tratamento secundário seguido de filtração e desinfecção. Em relação à irrigação restrita a OMS não menciona a turbidez como critério de adequação.

Na Figura 2 estão apresentados os valores médios de turbidez dos efluentes do reator UASB e do sistema UCT. Os resultados para o efluente do reator UASB não são aceitáveis para o uso irrestrito na agricultura apresentando um valor médio de 32,4 NTU e não são próprios para o uso em sistemas de gotejamento e aspersão. Para o sistema UCT o valor médio de turvação foi de 8,9 UNT, valor este também acima do limite de 2 NTU para irrigação irrestrita. 


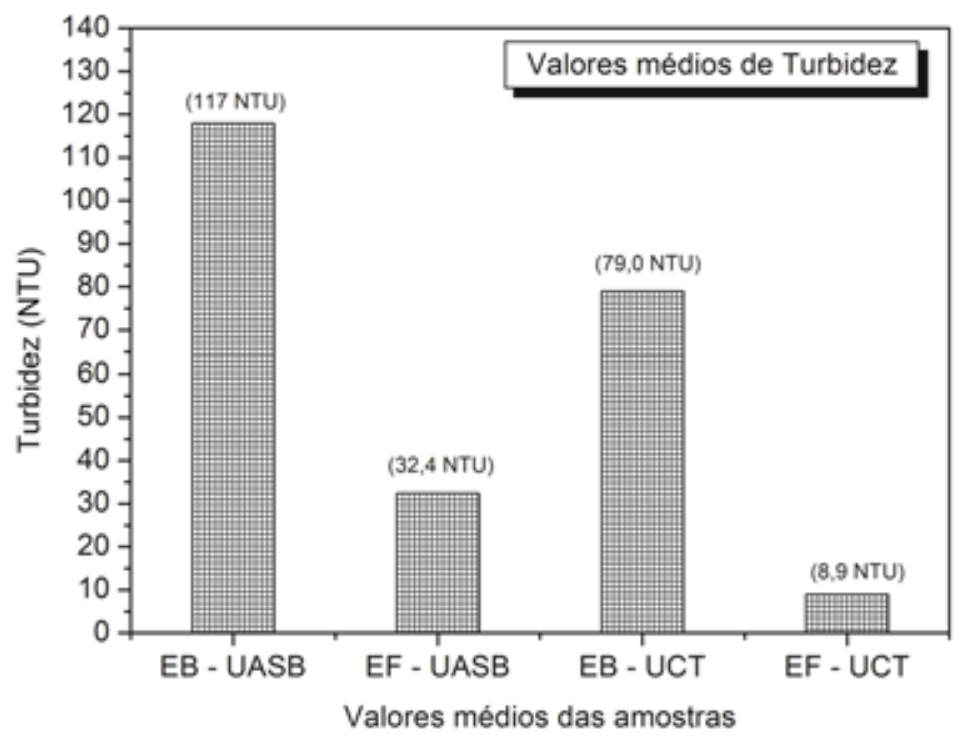

Figura 2. Valores médios de turbidez

A fim de reduzir a turbidez, a aplicação de um método de tratamento avançado eficaz como filtração em areia é sugerida como essencial antes do processo de desinfecção. Com uma unidade de filtração, além da maior redução dos valores de SST, o tratamento resultará também em uma melhor remoção de coliformes totais (CT) na unidade de desinfecção (BAKOPOULOU et al., 2011).

\subsection{SÓLIDOS SUSPENSOS TOTAIS (SST)}

Quando são utilizadas as águas residuárias em sistemas de gotejamento, os problemas com entupimento dependem do nível de tratamento (se removem eficientemente os materiais sólidos) e da sazonalidade (como hora do dia e estação do ano), visto que precipitações prolongadas resultam em elevado escoamento superficial que pode carrear materiais particulados para o sistema de irrigação. Efluentes com concentrações elevadas de sólidos em suspensão e de matéria orgânica podem causar entupimento de emissores (SCISCHA et al., 1996; BARBAGALLO et al., 2002).

O efluente do reator UASB apresentou um valor médio de $70,0 \mathrm{mg} . \mathrm{L}$ ${ }^{1}$ (Figura 3), resultado este dentro da faixa relatada pela literatura: de 60 a $100 \mathrm{mg} . \mathrm{L}^{-1}$ 
(VON SPERLING, 2002). Conforme as classes de restrição preconizadas por Ayres e Westcot (1991), para a concentração de sólidos suspensos do efluente do reator UASB, os resultados variaram entre nenhuma, moderada e severa restrição de uso para irrigação.

Efluentes enquadrados como moderados e, principalmente, com severa restrição podem obstruir os sistemas de irrigação por aspersão ou gotejamento, sendo esses efluentes mais indicados para uso em sistemas de irrigação por sulco (SOUSA et al., 2006).

O sistema de lodo ativado (UCT), em relação aos sólidos, apresentou valor médio de $25 \mathrm{mg} . \mathrm{L}^{-1}$, com todos os dados menores que $50 \mathrm{mg} . \mathrm{L}^{-1}$, não apresentando nenhuma restrição de uso quanto ao risco de obstrução de sistemas de irrigação localizada, dispensando etapas de polimento quanto a este parâmetro.

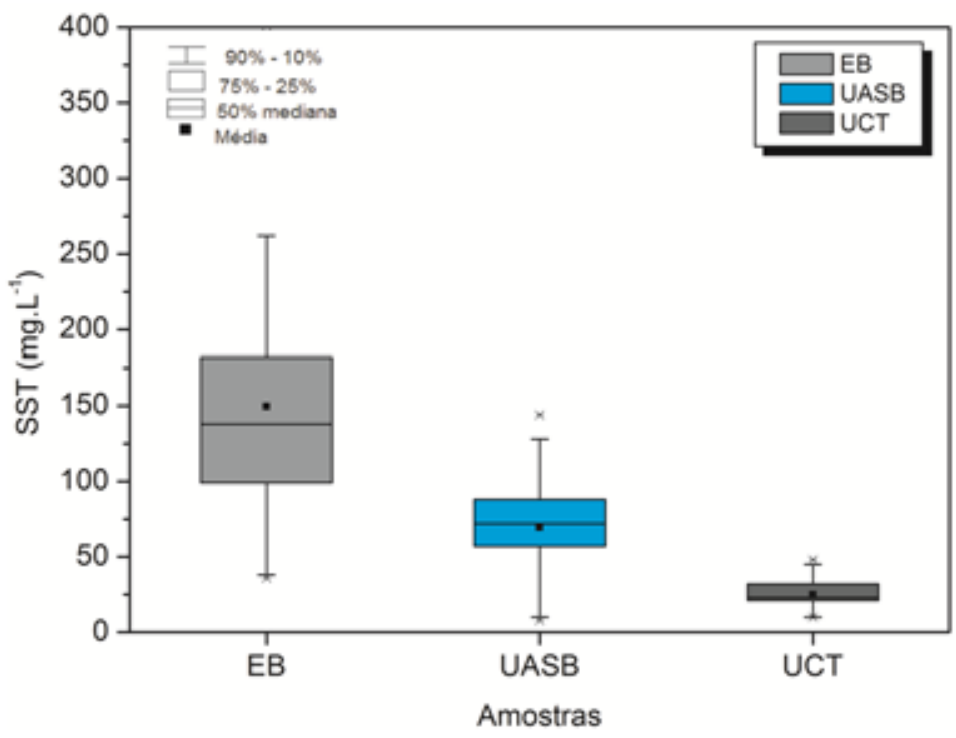

Figura 3. Resultados de SST para esgoto bruto e tratado nos reatores

Para o uso de efluente do reator UASB na irrigação por gotejamento seria necessário adotar um pós-tratamento. Capra e Scicolone (2004) afirmam que o entupimento de gotejadores é o maior problema de manutenção em sistemas de gotejamento e que a filtração é a principal defesa contra entupimentos causados 
pelas partículas minerais e orgânicas, estando entre os mais comumente utilizados os filtros de tela, filtros de disco e os filtros de areia e cascalho.

\subsection{DEMANDA QUÍMICA DE OXIGÊNIO (DQO)}

De acordo com a Figura 4, o reator UASB apresentou uma remoção média dos compostos orgânicos de $63 \%$, muito próximo da faixa relatada pela literatura para estes sistemas que é de até 70\%. A DQO média do período amostral foi de 99,0 mg.. $\mathrm{L}^{-1}$, bastante similar ao limite estabelecido de $100 \mathrm{mg} . \mathrm{L}^{-1}$, podendo estes efluentes servirem como condicionantes do solo no processo de irrigação.

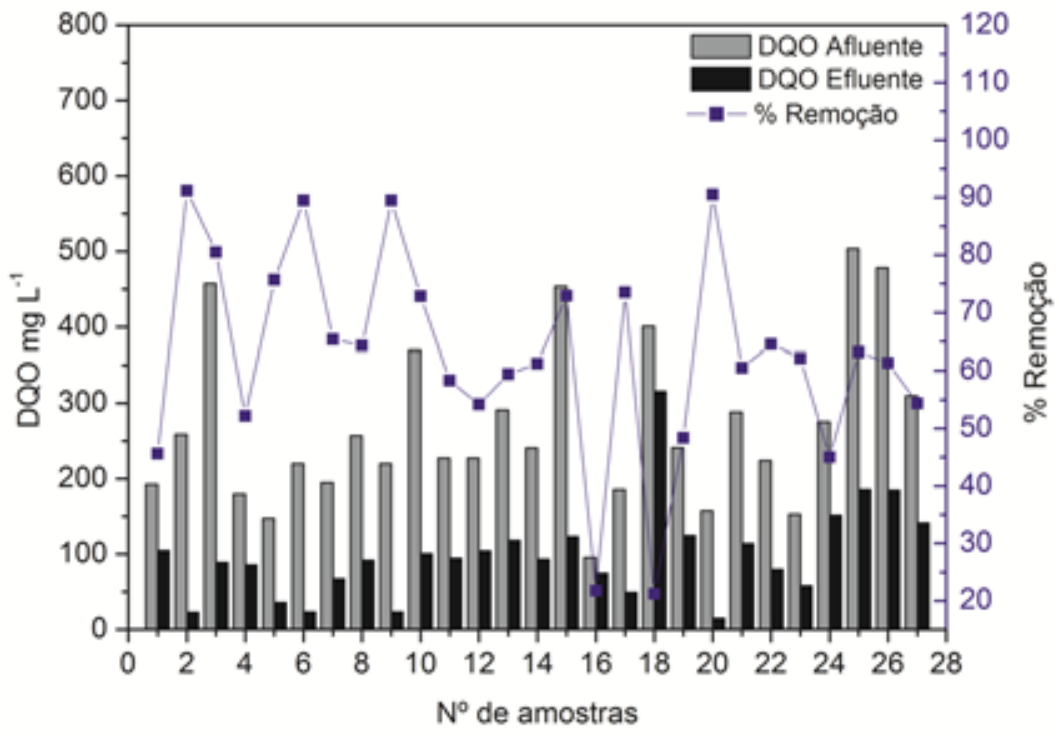

Figura 4. Remoção de matéria orgânica no reator UASB

Observando a Figura 5, é possível notar que o sistema UCT apresentou remoção média de $80 \%$ de matéria orgânica, abaixo da faixa relatada pela literatura que é de 93\% a 98\% (VON SPERLING, 2002; BARROS, 2014; LIMA et al., 2014).

Conforme análise dos estudos desses autores é possível atribuir a essa menor eficiência problemas operacionais como controle do oxigênio dissolvido e concentração de material orgânico, para manutenção de uma relação alimento 
microrganismo adequada, bem como boa sedimentabilidade, visto que o esgoto utilizado, por ser proveniente de atividades de uma instituição de ensino, variava suas características, principalmente em períodos sem atividades no Campus (LIMA et al., 2013).

A concentração média efluente de DQO foi de $93 \mathrm{mg} . \mathrm{L}^{-1}$, valor dentro dos limites estabelecidos de $100 \mathrm{mg} . \mathrm{L}^{-1}$, que foram definidos para evitar problemas de absorção de água nas raízes das plantas (HESPANHOL, 2003).

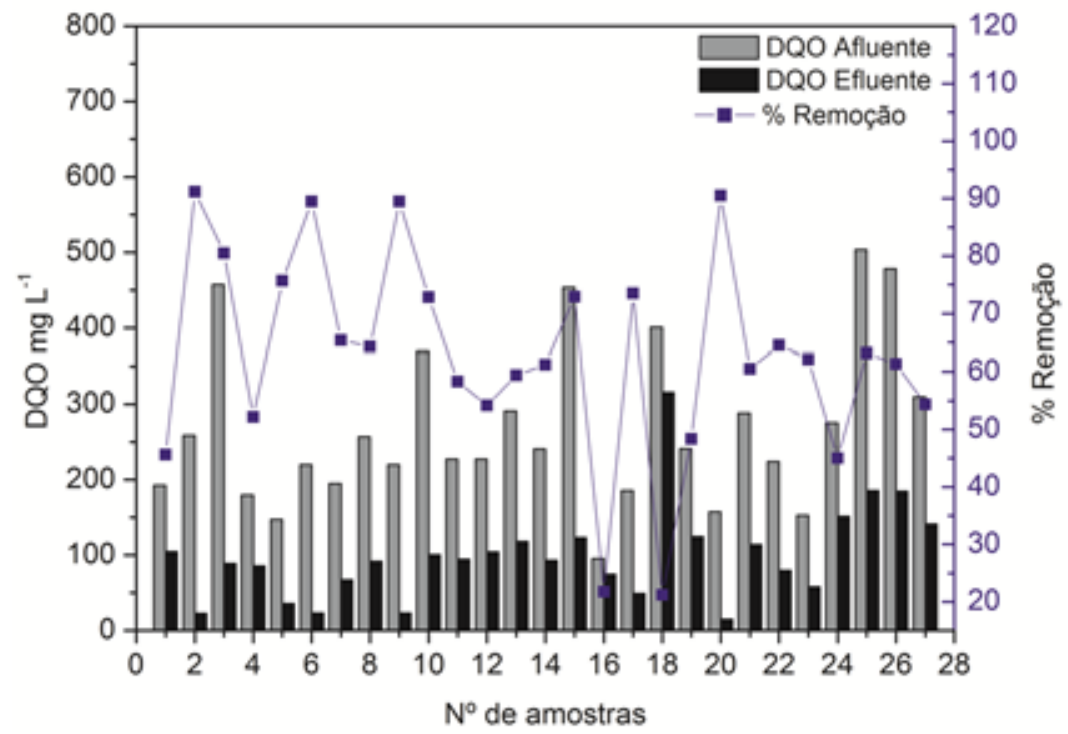

Figura 5. Remoção de matéria orgânica no Sistema UCT

\subsection{APORTE DE NUTRIENTES AO SOLO}

Os macronutrientes nitrogênio e fósforo permaneceram no efluente tratado dos dois sistemas em concentrações elevadas, um possível uso dessas águas vem a favorecer a fertilização dos solos e a produtividade de culturas.

O sistema de lodo ativado projetado para remoção de nutrientes apresentou menores valores de $\mathrm{N}$ e $\mathrm{P}$ efluentes quando comparado ao reator UASB, que, como esperado, não apresentou boa eficiência na remoção de nutrientes, devido ser uma tecnologia anaeróbia em que, biologicamente, não é possível a remoção de fósforo, 
e a de nitrogênio só seria possível em idêntica configuração física, caso houvesse predominância de lodo Anammox, lodo este autotrófico anaeróbio desnitrificante que utiliza tanto amônia quanto nitrito reduzindo o nitrito a nitrogênio gasoso (JENKINS et al., 2003).

Adotando uma aplicação de $2000 \mathrm{~mm}$ anuais (quantidade de água suficiente para a grande maioria das culturas em regiões semiáridas) e considerando os valores médios de fósforo total $6,7 \mathrm{mg} . \mathrm{L}^{-1}$ do sistema UASB e 4,81 mg.. $\mathrm{L}^{-1}$ na saída do sistema de lodo ativado representaria uma aplicação no solo de $134 \mathrm{Kg}^{-h^{-1}}$ ano $^{-1}$ e 96 $\mathrm{Kg} \mathrm{ha}^{-1}$.ano ${ }^{-1}$ respectivamente, uma aplicação que elimina a necessidade de emprego de fertilizantes comerciais com base de fósforo (AYRES; WESTCOT, 1991).

De acordo com os autores supracitados, o nitrogênio que pode agir também como fertilizante, quando em concentrações excessivas, pode causar dano às culturas agrícolas. Teores de nitrogênio total abaixo de $5 \mathrm{mg} . \mathrm{L}^{-1}$ são tidos como não causadores de problemas, afetando muito pouco as culturas agrícolas mais sensíveis. Acima de $30 \mathrm{mg} . \mathrm{L}^{-1}$ pode ser absorvido pelas plantas, sendo muito perigoso para algumas culturas. Além disso, o crescimento vegetativo excessivo em detrimento à produção agrícola é característico de culturas irrigadas com água contendo excesso de nitrogênio.

O sistema UCT apresentou uma concentração média de NTK efluente de $25,0 \mathrm{mg} . \mathrm{L}^{-1}$ e o reator UASB uma concentração média de $100 \mathrm{mg} . \mathrm{L}^{-1}$ (Tabela 1 ). Os valores bastante elevados na saída do reator UASB podem trazer problemas às culturas irrigadas contribuindo para um crescimento excessivo, confirmando a baixa eficiência na remoção de nutrientes.

A elevada carga de nitrogênio no esgoto bruto encontra-se discrepante às características típicas de esgoto doméstico, o que pode ter contribuído para a dificuldade na manutenção de um lodo estável ao longo do processo operacional do sistema de lodo ativado, que apesar de ter se mostrado superior na remoção desses nutrientes que o sistema UASB, não foi compatível com o esperado para sua configuração (VAN HAANDEL; VAN DER LUBBE, 2012).

O sistema UCT demonstrou uma boa remoção de nitrogênio com eficiência de 78\%, apresentando concentrações ideais para água aplicada na irrigação (Tabela 1). Para uma aplicação de $200 \mathrm{~mm}$ anuais, os valores médios de NTK para o sistema 
anaeróbio e de lodo ativado teriam, respectivamente, $2000 \mathrm{Kg}^{-h^{-1}}$ ano $^{-1}$ e 500 Kg.ha-1 ano $^{-1}$.

Tabela 1. Valores de N e P presentes no esgoto bruto e após o tratamento

\begin{tabular}{|c|c|c|c|c|c|c|c|c|}
\hline \multirow{3}{*}{ Valores } & \multicolumn{4}{|c|}{ Fósforo $\left(\mathrm{mg} \cdot \mathrm{L}^{-1}\right)$} & \multicolumn{4}{|c|}{ Nitrogênio (mg. $\left.\mathbf{L}^{-1}\right)$} \\
\hline & \multicolumn{2}{|c|}{ UASB } & \multicolumn{2}{|c|}{ UCT } & \multicolumn{2}{|c|}{ UASB } & \multicolumn{2}{|c|}{ UCT } \\
\hline & Entrada & Saída & Entrada & Saída & Entrada & Saída & Entrada & Saída \\
\hline Média & 7,37 & 6,70 & 6,38 & 4,81 & 119,0 & 100,0 & 119,0 & 25,0 \\
\hline Mínimo & 2,76 & 3,25 & 1,48 & 1,29 & 96,0 & 87,0 & 95,0 & 7,0 \\
\hline Máximo & 10,22 & 9,36 & 10,84 & 8,50 & 134 & 118,0 & 138 & 35,0 \\
\hline $\begin{array}{l}\text { Remoção } \\
\%\end{array}$ & \multicolumn{2}{|c|}{9,1} & \multicolumn{2}{|c|}{24,6} & \multicolumn{2}{|c|}{15} & \multicolumn{2}{|c|}{78} \\
\hline
\end{tabular}

\subsection{TOXICIDADE ÀS PLANTAS E RISCO DE SALINIZAÇÃO E SODIFICAÇÃO DO SOLO}

Quanto à toxicidade às plantas pela presença do íon $\mathrm{Cl}$; os efluentes gerados se apresentaram com nenhuma a moderada restrição de uso. Assim como o sódio, que apresentou valores médios entre 2,93 e 8,40 mmolc. $\mathrm{L}^{-1}$ no reator UASB e 2,53 e 7,15 mmolc. $\mathrm{L}^{-1}$ no UCT, e conforme os resultados da RAS entre 3,0 e 9,0 mmolc. $\mathrm{L}^{-1}$, apresentaram-se com moderada toxicidade às plantas para as águas de ambos os sistemas.

A condutividade elétrica apresentou valores consideráveis, tanto para o esgoto bruto quanto para o esgoto tratado, com valores médios em torno de 1.200 $\mu \mathrm{S} . \mathrm{cm}^{-1} \mathrm{e}$ valor máximo determinado de $1700 \mu \mathrm{S} . \mathrm{cm}^{-1}$. Esta constatação evidencia que, por ser o sal parte da dieta humana e o tratamento biológico não remover sais, a irrigação com efluentes de esgotos domésticos pode trazer efeitos deletérios para o crescimento das plantas, em virtude do aumento dos sais, caso não se tenha um manejo adequado de irrigação e drenagem. Na Tabela 2 é demonstrada a similaridade dos resultados para o esgoto bruto e esgoto tratado do reator UASB e UCT com dados de condutividade elétrica média e valores mínimo e máximo idênticos (NAVAL; ABRÃO JÚNIOR, 2012). 
Segundo Ayres e Westcot (1991) e Asano et al. (1998), as águas que apresentam condutividade elétrica entre 700 e $3000 \mu \mathrm{S} . \mathrm{cm}^{-1}$, como é o caso do efluente da pesquisa, apresentam moderada restrição de uso na irrigação.

Tabela 2. Estatística básica para os resultados de cloretos e CE

\begin{tabular}{lccc|ccc}
\hline \multirow{2}{*}{ Estatística } & \multicolumn{3}{c|}{ Cloretos $\left(\mathbf{m m o l c}^{-1}\right)$} & \multicolumn{3}{c}{ CE $\left(\mu\right.$ S.cm $\left.^{-1}\right)$} \\
\cline { 2 - 7 } & $\begin{array}{c}\text { Esgoto } \\
\text { Bruto }\end{array}$ & $\begin{array}{c}\text { Efluente } \\
\text { UASB }\end{array}$ & $\begin{array}{c}\text { Efluente } \\
\text { UCT }\end{array}$ & $\begin{array}{c}\text { Efluente } \\
\text { Bruto }\end{array}$ & $\begin{array}{c}\text { Efluente } \\
\text { UASB }\end{array}$ & $\begin{array}{c}\text { Efluente } \\
\text { UCT }\end{array}$ \\
\hline Mínimo & 2,99 & 2,92 & 3,21 & 538 & 600 & 538 \\
Média & 5,41 & 5,29 & 6,15 & 1248 & 1249 & 1259 \\
Máximo & 8,75 & 8,57 & 8,75 & 1725 & 1753 & 1753 \\
$\begin{array}{l}\text { Desvio } \\
\text { padrão }\end{array}$ & 2,32 & 2,18 & 1,68 & 302 & 286 & 276 \\
$\begin{array}{l}\text { Variância } \\
\text { (\%) }\end{array}$ & 43 & 41 & 27 & 18 & 16 & 16 \\
\hline
\end{tabular}

A água tratada nos dois sistemas com condutividade média em torno de $1200 \mu \mathrm{S} . \mathrm{cm}^{-1}$, e RAS com valores em torno de 4,0, é agrupada na classe de moderada restrição de uso (Tabela 3). Os valores relativamente baixos da RAS e valores moderados de salinidade significa que pode ser esperada sobre o solo uma redução da taxa de infiltração de leve a moderada. Estas águas não devem ser utilizadas como água de irrigação para os solos que têm redes de drenagem limitada, podendo ser usadas como água de irrigação no solo com boa drenagem e no caso de culturas tolerantes ao sal.

A opção pelo nível de tratamento complementar como ultrafiltração para remoção de sais é ainda dependente principalmente do tipo de solo e cultura irrigada e ainda de recursos devido ao preço elevado dessa tecnologia.

Tabela 3. Riscos de sodicidade do esgoto bruto e tratado

\begin{tabular}{cccc}
\hline Amostra & RAS & CE $\left(\mathrm{ds} . \mathrm{cm}^{-1}\right)$ & Classe \\
\hline EB & 4,21 & 1,24 & Moderada \\
UASB & 4,82 & 1,24 & Moderada \\
UCT & 4,80 & 1,33 & Moderada \\
\hline
\end{tabular}




\subsection{DETERMINAÇÃO DE COLIFORMES E OVOS DE HELMINTOS}

Os maiores riscos de contaminação por patógenos estão associados, normalmente, à utilização de efluentes de esgotos não tratados na irrigação de lavouras ocasionando riscos aos consumidores, bem como aos trabalhadores rurais (SANTAMARIA; TORANZOS, 2003).

De acordo com Santos (2008), a prática de irrigação com esgoto não é isenta de riscos e tem potencial de transmissão de doenças, pois patógenos presentes neste subproduto podem sobreviver no sistema solo-planta.

A transmissão de doenças é controlada por fatores agronômicos como método de irrigação empregado, crescimento da planta, práticas de cultura e de colheita (AYRES; WESTCOT, 1991).

Em relação ao monitoramento do padrão bacteriológico através dos coliformes termotolerantes, o esgoto bruto apresentou um valor médio de $1,7.10^{7}$ NMP.100 mL $\mathrm{m}^{-1}$ e os efluentes dos sistemas UASB e UCT uma concentração média de 2,1.10 NMP. $100 \mathrm{~mL}^{-1}$ e 2,6.10 ${ }^{4}$ NMP. $100 \mathrm{~mL}^{-1}$, respectivamente, demonstrando uma redução aproximada da ordem $1 \log$ e $3 \log$ de bactérias do grupo coliformes (Tabela 4).

Observa-se que houve um decréscimo de aproximadamente $85 \%$ no reator UASB, valor próximo ao registrado por Van Haandel e Lettinga (1994), 80\% em monitoramento realizado por 30 semanas em reatores UASB e 99,9\% no sistema UCT. A maior remoção no sistema de lodo ativado pode estar relacionada aos mecanismos de aeração e sedimentação do lodo em que ocorre adsorção dos microrganismos aos flocos (GOBBI, 2010).

Tabela 4. Resultados de coliformes e ovos de helmintos das amostras analisadas

\begin{tabular}{|c|c|c|c|c|c|c|}
\hline \multirow{3}{*}{ Estatística } & \multicolumn{3}{|c|}{$\begin{array}{c}\text { Coliformes termotolerantes } \\
\left(\mathrm{NMP} .100 \mathrm{~mL}^{-1}\right)\end{array}$} & \multicolumn{3}{|c|}{$\begin{array}{c}\text { Ovos de Helmintos } \\
\left(\text { Ovos. } \mathrm{L}^{-1}\right)\end{array}$} \\
\hline & Efluente & Saída & Saída & Efluente & Saída & Saída \\
\hline & Bruto & UASB & UCT & Bruto & UASB & UCT \\
\hline Mínimo & $1,7.10^{6}$ & $8,0.10^{4}$ & $1,3 \cdot 10^{4}$ & 14,0 & 18,8 & 0,8 \\
\hline Média & $1,7.10^{7}$ & $2,1.10^{6}$ & $2,6 \cdot 10^{4}$ & 18,8 & 26 & 4,9 \\
\hline Máximo & $5,0.10^{7}$ & $5,0.10^{6}$ & $50.10^{4}$ & 26,0 & 4,0 & 12 \\
\hline $\begin{array}{l}\text { Re m o çã o } \\
(\%)\end{array}$ & - & 85,0 & 99,9 & - & 87 & 95 \\
\hline
\end{tabular}


Considerando apenas o padrão bacteriológico das novas diretrizes da $\mathrm{WHO}$ (2006), referente ao reuso agrícola, para os valores máximos determinados de $10^{6}$ no sistema UASB o efluente poderia ser utilizado na irrigação restrita subsuperficial e seguindo a diretriz para valores $\leq 10^{5}$, enquanto que o efluente do sistema de lodo ativado poderia ser aplicado na irrigação irrestrita e localizada de plantas que se desenvolvem distantes do nível do solo ou na irrigação restrita com alto nível tecnológico e altamente mecanizada.

Os efluentes apresentaram alta concentração de bactérias para serem recomendados no uso agrícola irrestrito no caso de raízes e tubérculos, folhosas ou de plantas que se desenvolvem rentes ao nível do solo, havendo a necessidade de um tratamento complementar.

A produção de efluentes tratados com baixa densidade de coliformes fecais (por exemplo, $\mathrm{CF}<10^{3} \mathrm{NMP} .100 \mathrm{~mL}^{-1}$ ) é possível por meio do emprego de processos naturais ou físico-químicos concebidos especificamente para a desinfecção. Estudos sugerem que o tratamento do esgoto, atrelado à cloração do efluente diminuem a concentração de coliformes na água, minimizando os riscos associados à presença de outros microrganismos potencialmente presentes nessas águas (ASANO et al.,1998; TANAKA et al.,1998; YOUN-JOO et al., 2007).

Na remoção de ovos de helmintos, considera-se a eficiência do UASB como resultado de filtração e agregação dos grânulos biológicos na manta de lodo (VAN HAANDEL; LETTINGA, 1994; METCALF; EDDY, 2003).

No sistema de lodo ativado a sedimentação e aeração são operações responsáveis pela redução dos organismos patogênicos, sendo a sedimentação mais efetiva na remoção de patógenos de maior tamanho, como ovos de helmintos (GOBBI, 2010).

Para ovos de helmintos, os efluentes do UASB e UCT com concentrações respectivamente de 18,8 e 4,9 ovos. $\mathrm{L}^{-1}$ inviabiliza o reúso na agricultura, não se enquadrando no padrão de irrigação que é de um valor médio menor que 1 ovo.L ${ }^{-1}$ (WHO, 2006).

A implementação de um tratamento terciário se faz necessária para ambos os sistemas, entre os mais estudados pela bibliografia especializada pode-se optar pela filtração, sedimentação e desinfecção, visando à adequação para os padrões microbiológicos. 


\section{CONSIDERAÇÕES FINAIS}

Os sistemas de tratamento UASB e UCT tratando esgoto com alta relação nitrogênio-material orgânico só cumpriram parcialmente os requisitos para reúso agrícola. O sistema UASB apresentou SST e turbidez como limitantes na irrigação localizada, concentração de coliformes apenas para irrigação restrita em subsuperfície, NTK acima de $30 \mathrm{mg} . \mathrm{L}^{-1} \mathrm{e}$ a contagem $>1,0$ ovo. $\mathrm{L}^{-1}$ de helmintos que inviabiliza o reúso conforme o padrão de $<1$ ovo. $\mathrm{L}^{-1}$ definido pela Organização Mundial de Saúde.

O sistema UCT apresentou menos limitações de acordo com os parâmetros avaliados, porém com inviabilidade de reúso direto principalmente devido à turbidez e aos parâmetros microbiológicos de coliformes e ovos de helmintos.

Os sistemas avaliados apresentam risco moderado quanto à salinização do solo, sodicidade e toxicidade às plantas, devido aos sais passarem de forma inalterável pelos sistemas UASB e UCT, necessitando de um manejo de irrigação adequado.

A presença de macronutrientes ( $\mathrm{N}$ e $\mathrm{P}$ ) presentes nos efluentes favorece a fertilização do solo, eliminando o uso de fertilizante comercial, trazendo benefícios econômicos além de um possível aumento de produtividade. No caso do sistema anaeróbio, os teores elevados de nitrogênio podem trazer problemas agronômicos. Ao contrário do nitrogênio, teores excessivos dos compostos de fósforo nos sistemas trazem benefício não sendo reportados na literatura como causadores de problemas às culturas agrícolas, podendo ser reaproveitado em sua totalidade.

Conforme exposto, águas residuárias com características similares ao desta pesquisa, tratadas em sistemas UASB e UCT, podem ser empregadas na agricultura desde que passem por um tratamento complementar, vindo a minimizar os impactos sobre a interface solo-planta, garantindo um aporte de nutrientes às culturas irrigadas, contribuindo para a diminuição de custos com fertilizantes e fundamentalmente não oferecendo riscos à saúde pública.

\section{REFERÊNCIAS}

AYRES, R. S.; WESTCOT, D. W. A qualidade da água na agricultura. Tradução de Ghevi, H. R.; Medeiros, F. Campina Grande: UFPB, 1991. 218p. 
AYRES, R.; MARA, D. Analysis of wastewater for use in agriculture: A laboratory manual of parasitological and bacteriological techniques. WHO: Geneva, 1996.

APHA; AWWA; WEF. Standard methods for the examination of water and wastewater. $22^{\text {th }}$ ed. Washington, DC: [s.n.], 2012. 1368p.

ASANO, T.; ECKENFELDER, W. W.; MALINA JR., J. F.; PATTERSON, J. W. Wastewater reclamation and reuse. Califórnia: CRC, 1998. 1135p.

BAKOPOULOU, S.; EMMANOUIL, C.; KUNGOLOS, A. Assesdment of wastewater effluent quality in Thessaly region, Greece, for determining its irrigation reuse potential. Ecotoxicology and Environmental, v. 74, p. 188-194, 2011.

BARBAGALLO, S.; CAPRA, A.; PICCIONE, G.; SCICOLONE, B. Irrigazione a goccia con acque reflue urbane. Prove di erogatori e di filtri. (Drip irrigation using municipal wastewater. Emitter and filter tests). In: PROCEEDINGS OF THE QUINTA CONFERENCIA CIENTIFICA INTERNACIONAL UNICA, Ciego de Avila, Cuba, October.

BARROS, A. R. M. Avaliação dos parâmetros cinéticos de biomassa gerada em sistemas de lodo ativado. 2014. 103f. Dissertação (Mestrado) - Universidade Federal de Campina Grande, UFCG, 2014.

BRITO, L. P. Mercado de reúso de água no Brasil: é possível assegurar um crescimento sem a definição de um arcabouço normativo e legal? Revista DAE, São Paulo, v. 188, p. 8. 2012.

CAPRA, A.; SCICOLON, B. Emitter and filter tests for wastewater reuse by drip irrigation. Agricultural Water Management, v. 68, p. 135-149, 2004.

CHERNICHARO, C. A. L.; FLORENCIO, L.; BASTOS, R. K. X.; PIVELI, R. P.; VON SPERLING, M.; MONTEGGIA, L. O. Tratamento de esgotos e produção de efluentes adequados a diversas modalidades de reúso da água. In: FLORENCIO, L.; BASTOS, R. K. X.; AISSE, M. M. (Coord.). Tratamento e utilização de esgotos sanitários. Rio de Janeiro: ABES, 2006. 427p. 
GOBBI, S. A. Remoção de ovos de helmintos de esgotos secundários, por meio de filtros rápidos de areia, carvão antracitoso e zeólito para reúso agrícola e urbano não potável. 2010. 99f. Dissertação (Mestrado em Engenharia Hidráulica e Sanitária) - Escola Politécnica da Universidade de São Paulo, São Paulo, 2010.

HESPANHOL, I. Potencial de reúso no Brasil: Agricultura, indústria, município e recarga de aquíferos. In: MANCUSO, P. C. S.; SANTOS, H. F. Reúso de água. São Paulo. USP, 2003.

JENKINS, D.; RICHARD, M. G.; DAIGGER, G. T. Manual on the causes and control of activated sludge bulking, foaming, and other solids separation problems. 3rd ed. Florida: Lewis Publishers; Boca Raton, 2003.

LIMA, J. F.; CHAVES, J. R.; SANTOS, E. V. M.; SILVA FILHO, H. A. Avaliação da sedimentabilidade da biomassa em diferentes sistemas de tratamento. In: Arminda Saconi Messias. (Org.). Gestão de Água: Água, Meio Ambiente e Saúde. Recife: UNICAPE, 2013, v. 1, p. 2.

LIMA, J. F.; SANTOS, E. V. M.; SILVA FILHO, H. A.; VAN HAANDEL, A. C.; SOUSA, J. T. Avaliação da sedimentabilidade de biomassa granular e floculenta em sistemas de lodo ativado. LEITE, J. Editorial. HOLOS, Natal. Disponível em: < http://www2.ifrn. edu.br/ojs/index.php/HOLOS/article/view/2128> . Acesso em: 20 ago. 2014.

METCALF; EDDY, INC. Wastewater engineering, treatment, disposal and reuse. USA: Mc Graw - Hill, 2003. 1819p.

NAVAL, L. P.; ABRÃO JÚNIOR, F. Reúso de esgoto tratado para fins agrícola. Palmas. 2011. 42p. Disponível em: < http://www.central2.to.gov.br/arquivo/31/64>. Acesso em: 31 out. 2012.

ORON, G.; CAMPOS, C.; GILLERMAN, L.; SALGOT, M. Wastewater treatment, renovation and reuse for agricultural irrigation in small communities. Agricultural Water Management, v. 38, p. 223-234, 1999.

RABINOWITZ, B.; MARAIS, G. V. R. Chemical and biological phosphorus removal in the activated sludge process. Research Report, Department of Civil Engineering, University of Cape Town, South Africa, 1980. 
SANTAMARIA, J.; TORANZOS, G. A. Entheric pathogens and soil: a short review. International. Microbiology, v. 6, p. 5-9, 2003.

SANTOS, C. H. Análise espectroscópica da matéria orgânica de solos sob aplicação de águas residuárias. 2008. 165f. Dissertação (Mestrado em Química Analítica) - Universidade de São Paulo, Instituto de Química de São Carlos, SP, 2008.

SCISCHA, A.; RAVINA, I.; SAGI, G.; PAZ, E.; YECHIELY, Z.; ALKON, A.; SCHRAMM, G.; SOFER, Z.; MARCU, A.; LEV, Y. Clogging control in drip irrigation systems using reclaimed wastewater-the platform trials. In: Proceedings of the Seventh International Conference on Water and Irrigation, Tel Aviv, Israel, 1996. p. 104114.

SOUSA, J. T.; CEBALLOS, B. S. O.; HENRIQUE, I. N.; DANTAS, J. P.; LIMA, M. S. Reúso de água residuária na produção de pimentão (Capsicum annum L.). Revista Brasileira de Engenharia Agrícola e Ambiental, v. 10, p. 1- 8, 2006.

TANAKA, H.; ASANO, T.; SCHROEDER, E. D.; TCHOBANOGLOUS, G. Estimating the safety of wastewater reclamation and reuse using enteric virus monitoring data. Water Environment Research, v. 70, p. 39-5, 1998.

TELLES, D.; COSTA, R. H. P. G. Reúso da água: teoria, conceito teorias e práticas. São Paulo: [s.n.], 2007. 311p.

USEPA. U. S. Environmental Protection Agency. Guidelines for Water Reuse. Washington, DC, 2004. 478p.

VAN HAANDEL, A.; LETTINGA, G. Tratamento anaeróbio de esgotos: um manual para regiões de clima quente. Campina Grande: Universidade Federal da Paraíba, 1994.

VAN HAANDEL, A.; MARAIS, G. O comportamento do sistema de lodo ativado: teoria e aplicações para projetos e operações. Campina Grande, [s.n.], 1999. 488p.

VAN HAANDEL, A. C.; VAN DER LUBBE, J. Handbook biological wastewater treatment, design and optimization of activate sludge systems. London, UK. 2012. 816p. 
VON SPERLING, M. Princípios do tratamento biológico de águas residuárias. v. 4. Lodos ativados. 2. ed. Belo Horizonte: DESA-UFMG, 2002. 428p.

WHO. World Health Organization. Guidelines for the safe of wastewater, excreta and greywater: policy and regulatory aspects. v. 1. Geneva: WHO, 2006. 114p.

YOUN-JOO, A.; YOON, C. G.; JUNG, K. W.; HAM, J. H. Estimating the Microbial risk of E. Coli Reclaimed Wastewater Irrigation on Paddy Field. Enron Monit Assess, v. 129. p. 53-60, 2007.

Recebido: 16 de junbo de 2014 Aceito: 01 de julbo de 2015 